\title{
Comparative investigation of border disease virus infection in sheep flocks with abortion problems in Konya province
}

\author{
Oguzhan Avci", Sibel Yavru \\ Department of Virology, Faculty of Veterinary Medicine, University of Selcuk, 42075, Konya, Turkey \\ Email address: \\ oavci@selcuk.edu.tr (O. Avci), sibelyavru@selcuk.edu.tr (S. Yavru)
}

\section{To cite this article:}

Oguzhan Avci, Sibel Yavru. Comparative Investigation of Border Disease Virus Infection in Sheep Flocks with Abortion Problems in Konya Province. Science Research. Vol. 2, No. 5, 2014, pp. 119-124. doi: 10.11648/j.sr.20140205.17

\begin{abstract}
The aim of the present study was to determine the serological and virological status of animals persistently infected (PI) with border disease virus (BDV), with focus on the prevalence of pestiviruses in sheep and lambs. This study is the first to our knowledge, to investigate the role of viral infections in abortions in the sheep population of Konya province. The prevalence of antibodies against BDV was as follows: sheep, 79\%; lambs, 43.4\%; and rams, $6 \%$. Of 1000 leukocyte (sheep) samples examined with a direct ELISA, 11 (1.1\%) (first sampling) were antibody-positive. Three sheep were determined to be PI and were sacrificed. Of 1011 sheep leukocyte samples, 14 were examined using a direct immunoperoxidase (IP) assay for BDV antigen, and 11 of $327(3.36 \%)$ tissue samples were positive. The BDV genome was detected in 14 of $63(22.2 \%)$ sheep leukocyte samples and 11 of $327(3.36 \%)$ tissue samples by one-step RT-PCR. The BDV genome could not be detected in any vaginal swab samples. The sensitivity and specificity rates between direct ELISA and direct IP were respectively $100 \%$ and $98.8 \%$ and the values were, respectively, $78.57 \%$ and $98.6 \%$ between direct ELISA and one-step RT-PCR and 100\% and 97.5\% between one-step RT-PCR and direct IP. In conclusion it was determinate that BDV has an important role as an etiologic agent in abortion causes in sheep population in Konya.
\end{abstract}

Keywords: Border Disease Virus, Direct ELISA, Immunoperoxidase, One Step RT-PCR

\section{Introduction}

Pestiviruses infect sheep, cattle, and pigs, and cause significant economic losses worldwide [1,2]. Border disease virus (BDV) belongs to the genus Pestivirus within the family Flaviviridae. The pestivirus genome possesses positive polarity and a single strand of RNA that is $12.3-12.7$ kilobases $(\mathrm{kb})$. The virus, $40-60 \mathrm{~nm}$ in diameter, is surrounded by a 5-7 $\mu \mathrm{m}$ thick membrane whose outer surface is lined with radial processes, characterized by helical symmetry [3]. The virus is inactivated at $56{ }^{\circ} \mathrm{C}$ for $30 \mathrm{~min}$ and is sensitive to lipid solvents, ultraviolet light, and disinfectants [4]. Two biotypes of pestiviruses have been distinguished according to their proliferation in the cell culture as cytopathic (CP) or non-cytopathic (NCP) [5]. BDV is further divided into 4 subgroups in accordance with its antigenic features and host species [6]. Besides these subgroups, 2 novel subgroups were established as BDV5 and BDV6 from the pestivirus isolates in France [7].

Among the natural hosts of pestivirus are ruminants and wild ruminants in addition to various single-toed animals and deer [8]. BDV infection was first reported in the sheep living at the border between Whales and England in 1959 [9].

The presence of the viral antigen in PI animals can also be determined by Enyme Linked Immunosorbent Assay (ELISA), which is a rapid technique most frequently applied to blood samples, although parenchymal tissue samples have also tested by this technique [10,11]. One of the most sensitive methods for identifying BDV remains virus isolation. Direct Immunoperoxidase (IP) [12] or other immunohistochemical techniques on tissue sections as well as an antigen-detecting ELISA and conventional polymerase chain reactions (PCR) and RT-PCR assays are also valuable methods for identifying BDV-infected animals [13]. The preferred specimens for antigen detection by ELISA or for PCR are spleen, brain, kidney, lung, and mesenteric lymph nodes [14].

BDV can be transmitted through the secretions and excretions of the infected animals in addition to aborted fetuses, fetal membranes, and infected blood [15]. The spread of ncp BDV occurs only through the secretions and excretions by persistently infected (PI) animals [16]. The 
clinical findings of transplacental infections include early embryo deaths, central nervous and skeletal system deformations, the birth of lambs with "Hairy Shaker" appearance, persistent viremia, and changes in skin and fleece [17].

The aim of the present study was to characterize PI animals with respect to their viral loads and presence of antiviral antibodies in sheep and lambs. It was also compared the ability of various methods to diagnose BDV infection.

\section{Material and Methods}

\subsection{Animals and Samples}

Table 1. Test samples.

\begin{tabular}{llllllllll}
\hline & Sera & & \multicolumn{3}{c}{ Leukocytes } & \multicolumn{3}{c}{ Vaginal swabs Fetuses Fetuses } \\
\cline { 2 - 9 } & Lambs & Ewes & Rams & Lambs & Ewes & Rams & Lambs & Ewes & Tissue \\
\hline Producer1 & 200 & 100 & 10 & 202 & 100 & 10 & 10 & 9 & 88 \\
Producer2 & 200 & 100 & 10 & 206 & 100 & 10 & 10 & 8 & 73 \\
Producer3 & 200 & 100 & 10 & 200 & 100 & 10 & 10 & 6 & 48 \\
Producer4 & 200 & 100 & 10 & 200 & 100 & 10 & 10 & 9 & 90 \\
Producer5 & 200 & 100 & 10 & 203 & 100 & 10 & 10 & 4 & 36 \\
Total & 1000 & 500 & 50 & 1011 & 500 & 50 & 50 & 36 & 36 \\
\hline
\end{tabular}

\subsection{ELISA Analyses}

Serum sample antibody inhibition percentage (AIP) is described below. The manufacturer's guidelines (Institute Pourquier, France) were strictly followed and samples were considered positive for AIP $<40 \%$; doubtful for $40 \%-50 \%$, and negative for $\geq 50 \%$. AIP was calculated as follows: AIP $(\%)=\left(\mathrm{OD}_{\text {sample }} / \mathrm{OD}_{\mathrm{NC}(\text { mean })}\right) \times 100$

Direct ELISA results were calculated for each sample the $\mathrm{S} / \mathrm{P}$ ratio (in \%):

$$
\frac{\mathrm{S}}{\mathrm{P}}(\%)=\frac{\left(\mathrm{OD}_{\text {sample }^{-}}-\mathrm{OD}_{\mathrm{NC}}\right)}{\left(\mathrm{OD}_{\mathrm{PC}(\text { mean })}-O \mathrm{DD}_{\mathrm{NC}}\right)} \times 100
$$

Samples were considered positive for an S/P (\%) $\geq 30$; doubtful for $25 \%-30 \%$, and negative for $\leq 25 \%$.

ELISA-antigen positive animals were sampled again 2 weeks later to verify if these animals corresponded to PI status or suffered a transient infection.

\subsection{Immunoperoxidase}

Madin-Darby Bovine Kidney (MDBK) cells, negative for pestivirus, for virus propagation from the samples were used. A cytopathogenic NADL (National Animal Disease Laboratory) reference strain of BVDV and ncp BVDV reference strains were used in IP test for positive control. Direct IP was performed as described earlier by Hyera et al. [18]. For cell culture studies, the MDBK cells were cultured in Dulbecco's Modified Eagle's Medium (DMEM) $+5 \%$ Fetal calf serum (FCS) a density of $1 \times 10^{5}$ cells $/ \mathrm{ml} /$ well using 96-well plates, and the cultures were incubated in an
The animals for the present study were randomly chosen from the 5 sheep flocks that were not vaccinated against pestiviruses in Konya province and its surrounding areas between 2006 and 2008. Akkaraman breed sheep were used in this study. Clinical signs, such as abort, stillbirth, death 1-2 days postpartum, joint disorders, and nervous symptoms in newborn lambs from the test herds were recorded. The study protocol was approved by the Veterinary Faculty Ethics Committee of Selcuk University (Report no: 2008/007). The number of samples examined in this study is summarized in Table 1. atmosphere of $5 \% \mathrm{CO}_{2}$ at $37^{\circ} \mathrm{C}$ for overnight.

\section{4. $R T-P C R$}

RNeasy Mini Kit (QIAGEN, 74106) to extract RNA from the leukocyte, tissue samples and the cp NADL were used as a virus control. QIAamp Viral RNA Mini Kit (QIAGEN, 52906) was used to extract RNA from the swab samples. The One-Step RT-PCR kit (QIAGEN, 210212) was used to perform one-step RT-PCR amplifications. The PCR primers were purchased from Metabion, Germany. The sequences of the primer for BDV were as follows: Forward, 5' TCGTGGTGAGATCCCTGAG 3', Reverse GCAGAGATTTTTTATACTAGCCTATRC 3' [19].

\subsection{Statistical Analyses}

Because of not able to obtain positive samples from every producer from the sera of the rams using indirect or direct ELISA, lamb and ram leukocyte samples, and sheep swabs, which correlated with the results of the one-step RT-PCR assays, it was not performed statistical comparisons for the producers. Minitab 12.1 version was used for statistical evaluations. To analyze the antibody against pestiviruses in sheep and lambs, data distribution was checked using the chisquared test. The chi-squared test was used to determine whether differences existed among the results collected from leukocyte samples using direct ELISA the results of sheep leukocyte samples analyzed with IP the differences among the tests; and whether the determination of BDV differed according to organs. The percentages pertaining to the samples were compared statistically to the results. To present the 
difference between the tests, the " 2 proportions" test was used.

\section{Results}

In the first sampling of 1000 leukocyte samples taken from the sheep and analyzed with direct ELISA, 11 of 1000 were positive for the presence of BDV antigen. While 11 samples were positive for, they were negative for the presence of BDV-specific antibodies. These animals were re-sampled 15 days after the first sampling. Of the 11 animals found to be positive for BDV antigen at the first sampling, 3 were positive but negative for antibodies against BDV. These 3 were found to be PI. In addition, 8 of 11 animals were negative for BDV antigen but antibody-positive. When the samples were analyzed using direct IP, none of 500 lamb and 50 ram leukocyte samples, or 50 vaginal swabs were positive for BDV antigen. However, 14 of 1011 sheep and 11 of 327 tissue samples were positive (Fig. 1 and 2).

The results obtain other tests are summarized in Table 2 and 3 .

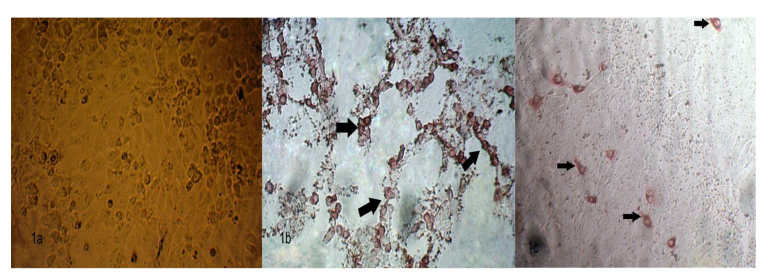

Fig 1. Direct immunoperoxidase test in madin darby bovine kidney. a) Cell control b) virus control (cp NADL strain) c) virus control (ncp BVDV strain) (x 200).

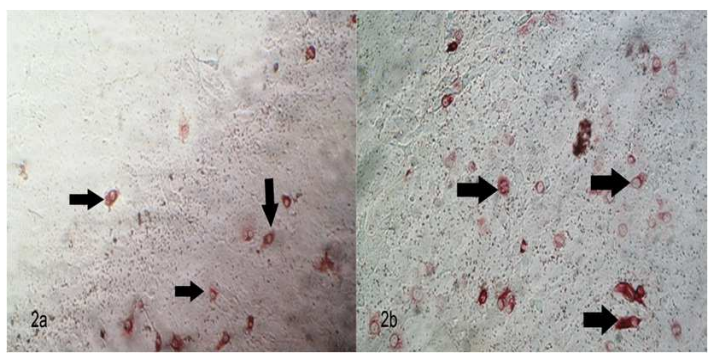

Fig 2. Direct immunoperoxidase test BDV antigen positive sample. a) leukocyte b) foetus liver (x 200).

Table 2. Results of indirect ELISA, direct ELISA, IP, and RT-PCR

\begin{tabular}{|c|c|c|c|c|c|}
\hline & & Indirect ELISA & Direct ELISA & IP & RT-PCR \\
\hline \multirow{3}{*}{ Sheep } & Leukocytes & NT & $11 / 1000(1.1 \%)$ & $14 / 1011(1.38 \%)$ & $14 / 63(22.2 \%)$ \\
\hline & Vaginal swabs & NT & $0 / 50$ & $0 / 50$ & $0 / 50$ \\
\hline & Sera & $790 / 1000(79 \%)$ & NT & NT & NT \\
\hline \multirow{2}{*}{ Lambs } & Leukocytes & NT & $0 / 500$ & $0 / 500$ & NT \\
\hline & Sera & $217 / 500(43.4 \%)$ & NT & NT & NT \\
\hline \multirow{2}{*}{ Rams } & Leukocytes & NT & $0 / 50$ & $0 / 50$ & NT \\
\hline & Sera & $3 / 50(6 \%)$ & NT & NT & NT \\
\hline Fetuses & Tissue & NT & $0 / 327$ & $11 / 327(3.36 \%)$ & $11 / 327(3.36 \%)$ \\
\hline
\end{tabular}

NT: not tested

Table 3. IP and One-step RT-PCR analysis results

\begin{tabular}{lcll}
\hline & & IP & One-step RT-PCR \\
\hline & n & BDV antigen positive & BDV genome positive \\
\hline Producer 1 & 409 & $3^{\mathrm{b}}$ & $3^{\mathrm{b}}$ \\
Producer 2 & 398 & $13^{\mathrm{a}}$ & $13^{\mathrm{a}}$ \\
Producer 3 & 368 & $-^{\mathrm{c}}$ & $-^{\mathrm{c}}$ \\
Producer 4 & 412 & $2^{\mathrm{b}}$ & $2^{\mathrm{b}}$ \\
Producer 5 & 351 & $7^{\mathrm{ab}}$ & $7^{\mathrm{ab}}$ \\
\hline
\end{tabular}

a,b,c: Statistically significant differences $(P<0.05)$ are indicated by different superscript letters. $\mathrm{n}$ : number of animals.

The sensitivity and specificity rates between direct ELISA and direct IP, were respectively $100 \%$ and $98.8 \%$ and the values were, respectively, $78.57 \%$ and $98.6 \%$ between direct ELISA and one-step RT-PCR and 100\% and $97.5 \%$ between one-step RT-PCR and direct IP.

\section{Statistical Analyses}

The outcomes of the statistical analyses indicated that the difference in the presence of BDV between the producers $(\mathrm{P}>0.05)$ and in the tissue samples $(\mathrm{P}>0.05)$ was not significant. According to the IP results and one-step RT-PCR assays there was a statistically significant difference between the producers (Table 3). No significant differences were present among the 3 tests $(\mathrm{P}>0.05)$. The variation between direct ELISA and one-step RT-PCR; between IP and one-step RT-PCR values were significant $(\mathrm{P}<0.05)$. In contrast, the deviation between direct ELISA and IP was not significant $(\mathrm{P}>0.05)$. The distribution of BDV among the organs was similar $(\mathrm{P}>0.05)$.

\section{Discussion}

Although the presence of pestivirus infections in animal populations can be determined using direct immunofluorescence (IF) and IP, its antigens can be detected using ELISA [10]. However, when the sensitivity and specificity of these tests are considered, the use of ELISA itself is not efficient, and the use of IP or RT-PCR in addition to ELISA is firmly suggested to detect BDV antigens [20]. In their studies performed in Turkey, Burgu et al. [21] and Simsek et al. [22] detected pestivirus antibodies $42.8 \%$ and $36.3 \%$, respectively. Here, it was obtained $79 \%$ seropositivity and conclude that this high rate was due to sampling herds carrying a high risk of BDV infection.

Cokcaliskan [23] examined samples using the direct IP method and isolated pestivirus in leukocyte samples of 1 
fetus. Hasircioglu et al. [24] reported the presence of pestivirus antigen in only $5(10.4 \%)$ of tissue samples of abortuses. In the present report, 327 tissue samples were analyzed and detected pestivirus in 11 samples (4 livers, 2 lungs, 2 brains, 1 heart, 1 spleen, 1 kidney) acquired from 4 fetuses (Table 2). In contrast to the study of Cokcaliskan [23] reporting presence of BDV in small intestine, in the present study, 14 small intestines, 4 thymuses, 4 lymph nodes, and 3 thyroid glands were inspected but did not detect virus markers in our assays. Attempted to determine if a particular organ in the body is better than the others for virus isolation; however, our statistical analyses indicated no marked significant difference in the incidence of the virus with respect to a particular organ. Others [14,20] have reported that skin, brain, kidney and thyroid gland appeared to be most reliable tissues for detecting the highest viral RNA loads. It can be established the tissues that the virus most likely attacks by focusing our specific studies toward its pathogenesis.

The presence of pestiviruses in rams has been investigated previously in Turkey [25]. In the present study, of the 50 rams sampled, $3(6 \%)$ of them were seropositive. This percentage was lower than the reported by Burgu et al. [25] and might simply reflect the effect of randomization. The low prevalence found in rams can be explained by the management conditions, because in some flocks, rams are reared in a separate group and consequently maintained far from infected animals. Moreover, the present study is the first, to our knowledge, to examine the seropositivity of rams living in Konya Province for pestivirus should prove to be useful for future studies in this area.

In the present study, it was observed $79 \%$ seropositivity, which is higher than reported by O'Neill et al. [26], Ataseven et al. [27], and Okur-Gumusova et al. [28]. The producers from which collected samples were suspected to have been infected by BDV. If so, this can explain the higher percentage of seropositivity reported here. Further, the high seroprevalence found in this study could be explained by the use of ELISA technique, which is more sensitive that other serological techniques used previously. Our one-step RTPCR results (Table 3) are similar to those reported by Oguzoglu et al. [29].

It is evaluated that sheep for the presence of pestivirus infection for the first time in Konya Province, and 3 sheep found to be infected. The infected sheep were removed from the heard to prevent disease spread and related economic losses. In addition, it was checked 50 breed stock rams for BDV infection, but since they were found to be negative, they were allowed to be used as breed stock.

The percentage of pestivirus infected sheep or viremic sheep ranges between $0.3 \%$ and $20 \%$ [30]. In the present study, it was found 11 animals positive for the presence of BDV antigen; however, these animals were also checked serologically and found to be negative for the presence of BDV specific antibodies, and the percentage of pestivirus infected animals was $0.3 \%$, a value lower than those reported by Valdazo-Gonzalez et al. [30] and Berriatua et al. [31].
These differences can be attributed to the effect of randomization of the results. One reason for the small number of PI animals could depend on the time in which the infection was established in the flock. Alternatively, it could be that the sampling was performed after the period of culling in the flocks, and consequently, PI animals were eliminated.

The studies of Willoughby et al. [32] indicate that colostral antibodies can mask the presence of $\mathrm{BDV}$ in pestivirus infected animals and misrepresent the presence of BDV infected lambs. This observation might be explained by the presence of colostral antibodies in the dams.

In particular direct and indirect Elisa's techniques can be widely used in national control programs [33]. Nevertheless, the use of IP for detecting BDV should be used. Further, because the specificity and sensitivity of one-step RT-PCR is better than that of IP, it should also be used preferentially to detect BDV [20].

The animals sampled for the presence of BDV antigen and found to be positive using the direct ELISA, but seronegative for the presence of antibody against BDV using indirect ELISA, were re-sampled after 15 days. Detected 3 sheep that were infected with BDV that were still seronegative and considered them as PI. Therefore, they were eliminated from the heard to prevent spread of the pestivirus infection. In addition, 8 sheep were found to be seropositive for BDV infection when sampled for the second time, and these animals were considered to be acutely infected.

It is proposed that all of the breed stock should be are required to be checked for the presence of BDV. To control $\mathrm{BDV}$ in a flock, it is also important to ensure that replacement lambs are all negative for BDV.

Hairy shaker lambs only appear in some breeds of sheep, depending on the characteristics of their wool. Our results suggest that even in the absence of "Hairy Shakers," animals in herds should be inspected for the presence of pestivirus before being allowed to join an established herd. There are other clinical symptoms that often appear, such as stillbirth, abortion, neurological symptoms, joint disorders, and bone malformations, which must be considered as well. It may be suggested that sampling of ewes, rams, goats, cattle, and other species for the presence of BDV will be useful for determining transmission of the virus between species. Presence of BDV in wild animals should be checked in Turkey, as well.

In conclusion, for the first time to our knowledge, the presence of BDV infection in ewes and rams raised in Konya province and surrounding areas in Turkey, and BDV may be considered as an etiologic abortive agent in sheep.

\section{Acknowledgements}

This study was supported financially by the Scientific Research Council of Selcuk University (08102001) and summarized from $\mathrm{PhD}$ thesis of Oguzhan Avci. Abstract was published in the $5^{\text {th }}$ European Virology Congress, 2013. 


\section{References}

[1] Krametter-Froetscher, R., Kohler, H., Benetka, V., Moestl, K., Golja, F., Vilcek, S. and Baumgartner W. (2007). Influence of communal alpine pasturing on the spread of pestiviruses among Sheep and Goats in Austria: First identification of border disease virus in Austria. Zoonoses and Public Health, 54: 209-213.

[2] Kale, M., Yavru, S., Ata, A., Kocamuftuoglu, M., Yapici, O. and Hasircioglu, S. (2011). Bovine viral diarrhoea virus infection in relation to fertility in heifers. Journal of Veterinary Medical Science, 73: 331-336.

[3] Rasmussen, T. B., Reimann, I., Hoffmann, B., Depner, K., Uttenthal, A. and Beer, M. (2008). Direct recovery of infectious pestivirus from a full-length RT-PCR amplicon. Journal of Virological Methods, 149: 330-333.

[4] Rumenapf, T., Meyers, G., Stark, R. and Thiel, H. J. (1991). Molecular characterization of hog cholera virus. Archives of Virology, Supplementum, 3: 7-18.

[5] Fulton, R. W., Briggs, R. E., Ridpath, J. F., Saliki, J. T., Confer, A. W., Payton, M. E., Duff, G. C., Step, D. L. and Walker, D. A. (2005). Transmission of bovine viral diarrhoea virus $1 \mathrm{~b}$ to susceptible and vaccinated calves by exposure to persistently infected calves. Canadian Journal of Veterinary Research, 69: 161-169.

[6] Berriatua, E., Barandika, J. F., Aduriz, G., Hurtado, A., Estevez, L., Atxaerandio, R. and Garcia-Perez, A. L. (2006). Flock-prevalence of border disease virus infection in Basque dairy-sheep estimated by bulk-tank milk analysis. Veterinary Microbiology, 118: 37-46.

[7] Dubois, E., Russo, P., Prigent, M. and Thiery, R. (2008). Genetic characterization of ovine pestiviruses isolated in France, between 1985 and 2006. Veterinary Microbiology, 130: 69-79.

[8] Moennig, V., Frey, H. R., Liebler, E., Pohlenz, J. and Liess, B. (1990). Reproduction of mucosal disease with cytopathogenic bovine viral diarrhea virus selected in vitro. The Veterinary Record, 127: 200-203.

[9] Hughes, L. E., Kershaw, G. F. and Shaw, I. G. (1959). "B" or Border Disease: An undescribed disease of sheep. The Veterinary Record, 71: 313-317.

[10] Sandvik, T. (2005). Selection and use of laboratory diagnostic assays in BVD control programmes. Preventive Veterinary Medicine, 72: 3-16.

[11] Yavru, S., Kale, M., Gulay, M. S., Yapici, O., Bulut, O. and Ata, A. (2013). Effects of bovine viral diarrhoea virus on the fertility of cows. Acta Veterinaria Hungarica, 61: 2. DOI 10.1556/AVet.2013.008.

[12] Marco, I., Rosell, R., Cabezon, O., Beneria, M., Mentaberre, G., Casas, E., Hurtado, A., Lopez-Olvera, J. R. and Lavin, S. (2009). Serologic and virologic investigations into pestivirus infection in wild and domestic ruminants in the Pyrenees (NE Spain). Research in Veterinary Science, 87: 149-153.

[13] Xia, H., Vijayaraghavan, B., Belak, S. and Liu, L. (2011). Detection and identification of the atypical bovine pestiviruses in commercial foetal bovine serum batches. PloS One, 6: e28553.
[14] Hurtado, A., Sanchez, I., Bastida, F., Minguijon, E., Juste, R. A. and Garcia-Perez, A. L. (2009). Detection and quantification of pestivirus in experimentally infected pregnant ewes and their progeny. Virology Journal, 6: 189-196.

[15] Kittelberger, R. and Pigott, C. (2008). The use of pestivirus antigen ELISA currently available for the detection of hairy shaker disease/border disease virus in sheep. New Zealand Veterinary Journal, 56: 343-344.

[16] Gardiner, A. C., Nettleton, P. F. and Barlow, R. M. (1983). Virology and immunology of a spontaneous and experimental mucosal disease-like syndrome in sheep recovered from clinical border disease. Journal of Comparative Pathology, 93: 463-469.

[17] Monies, R. J., Paton, D. J. and Vilcek, S. (2004). Mucosal disease-like lesions in sheep infected with Border disease virus. The Veterinary Record, 155: 765-769.

[18] Hyera, J. M. K., Liess, B. and Frey, H. R. (1987). A direct neutralizing peroxidase-linked antibody assay for detection and titration of antibodies to bovine viral diarrhea virus. Journal of Veterinary Medicine B, 34: 227-239.

[19] Vilcek, S. and Paton, D. J. (2000). A RT-PCR assay for the rapid recognition of border disease virus. Veterinary Research, 31: 437-445.

[20] Garcia-Perez, A. L., Minguijon, E., Jesus, F. B., Aduriz, G., Povedano, I., Juste, R. A. and Hurtado, A. (2009). Detection of Border disease virus in fetuses, stillbirths, and newborn lambs from natural and experimental infections. Journal of Veterinary Diagnostic Investigation, 21: 331-337.

[21] Burgu, I., Ozturk, F., Akca, Y., Toker, A., Frey, H. R. and Liess, B. (1987). Investigations on the occurence and impact of bovine viral diarrhea (BVD) virus infections in sheep in Turkey. Dtsch Tierarztl Wochenschr, 94: 292-294.

[22] Simsek, A., Yavru, S. and Ozturk, F. (1997). The serologic survey on bovine viral diarrhea virus infections in sheep in Konya. Veterinarium, 8: 45-47.

[23] Cokcaliskan, C. (2000). Pestivirus infections of pregnant sheep and their fetuses. Ankara University Graduate School of Health Sciences. Doctorate Thesis, Ankara, Turkey.

[24] Hasircioglu, S., Kale, M. and Acar, A. (2009). Investigation of pestivirus infections in aborted sheep and goats in Burdur region. Kafkas Universitesi Veteriner Fakültesi Dergisi, 15: 163-167.

[25] Burgu, I., Akca, Y., Alkan, F., Ozkul, A., Karaoglu, T., BilgeDagalp, S., Oguzoglu, T. C. and Yesilbag, K. (2001). The serological and virological investigations and pathogenesis of BVDV infection in sheep during pre- and post-partum periods. Turkish Journal of Veterinary and Animal Sciences, 25: 551-557.

[26] O'Neill, G. R., O'connor, M. and O'rolly, J. P. (2004). A survey of antibodies to pestivirus in sheep in the Republic of Ireland. Irish Veterinary Journal, 57: 525-530.

[27] Ataseven, V. S., Ataseven, L., Tan, T., Babur, C. and Oguzoglu, T. C. (2006). Seropositivity of agents causing abortion in local goat breeds in Eastern and South-eastern Anatolia, Turkey. Revue de Medecine Veterinaire, 157: 545-550.

[28] Okur-Gumusova, S., Yazici, Z. and Albayrak, H. (2006). Pestivirus seroprevalence in sheep populations from inland and coastal zones of Turkey. Revue de Medecine Veterinaire, 157: 595-598. 
[29] Oguzoglu, T. C., Tan, M. T., Toplu, N., Demir, A. B., Dagalp, S. B., Karaoglu, T., Ozkul, A., Alkan, F., Burgu, I., Haas, L. and Greiser-Wilke, I. (2009). Border disease virus (BDV) infections of small ruminants in Turkey: A new BDV subgroup? Veterinary Microbiology, 135: 374-379.

[30] Valdazo-Gonzalez, B., Alvarez-Martinez, M. and GreiserWilke, I. (2006). Genetic typing and prevalence of Border disease virus (BDV) in small ruminant flocks in Spain. Veterinary Microbiology, 117: 141-153.

[31] Berriatua, E., Barandika, J., Aduriz, G., Atxaerandio, R., Garrido, J. and Garcia-Perez, A. L. (2004). Age-spesific seroprevalence of border disease virus and presence of persistently infected sheep in Basque dairy-sheep flocks. The Veterinary Journal, 168: 336-342.

[32] Willoughby, K., Valdazo-Gonzalez, B., Maley, M., Gilray, J. and Nettleton, P. F. (2006). Development of a real time RTPCR to detect and type ovine pestiviruses. Journal of Virological Methods, 132: 187-194.

[33] Fenton, A., Sinclair, J. A., Entrican, G., Herring, J. A., Malloy, C. and Nettleton, P. F. (1991). A monoclonal antibody capture ELISA to detect antibody to border disease virus in sheep serum. Veterinary Microbiology, 28: 327-333. 